\title{
Global poverty dynamics and resilience building for sustainable poverty reduction
}

\author{
LI Yuheng ${ }^{1,2}$, WU Wenhao ${ }^{3}$, WANG Yongsheng ${ }^{1}$ \\ 1. CAS Key Laboratory of Regional Sustainable Development Modeling, Institute of Geographic Sciences and \\ Natural Resources Research, CAS, Beijing 100101, China; \\ 2. College of Resources and Environment, University of Chinese Academy of Sciences, Beijing 100049, China; \\ 3. Faculty of Geographical Science, Beijing Normal University, Beijing 100875, China
}

\begin{abstract}
There is less than a decade left to accomplish the goal of ending global poverty by 2030. This paper investigates global poverty dynamics and finds a shift in the world's poverty gravity center from South Asia to Africa in the period 1990-2015. Sub-Saharan Africa has become the main battlefield for poverty reduction in the world. Global poverty reduction has been accompanied by political instability and local conflicts, economic marginalization, rural decline, and natural hazards as well as climate change which are jointly impacting the least developed areas and making the world's poverty reduction vulnerable to external shocks. The "STAR" scheme, including maintaining political stability, promoting targeted poverty alleviation, implementing regular assessments of poverty reduction initiatives, and revitalizing rural and poverty-stricken areas, is proposed with specific measures to enhance the resilience capacity of poverty alleviation in the world.
\end{abstract}

Keywords: poverty reduction; poverty gravity center; resilience building; sustainability

\section{Introduction}

As human society moved to the third decade of the 21 st century, it is necessary to consider and evaluate the possibility of achieving the United Nations' Sustainable Development Goals (SDGs) by 2030. "End poverty in all its forms everywhere" is the first goal among the 17 SDGs and it captured the attention of different countries and international communities (Tollefson, 2015). Looking back through human history since the Second World War, resolute cooperation among countries has led to national actions being taken to eradicate poverty, including efforts to: (1) provide basic needs for the poor to reduce hunger and malnutrition, ensure food security, education, primary health care, safe drinking water, and sanitation; (2) help more people to become employed and avoid unemployment; (3) promote gender balance and equity in decision-making processes at all levels; (4) broaden of women's political, economic, social, and cultural opportunities as well as independence and empowerment (Agola and Awange, 2014).

Received: 2020-11-04 Accepted: 2021-04-07

Foundation: National Natural Science Foundation of China, No.41771191

Author: Li Yuheng (1983-), PhD and Associate Professor, E-mail: liyuheng@igsnrr.ac.cn 
In recent decades, marked progress has been achieved in reducing global poverty. According to the World Bank, 1.22 billion people were lifted out of poverty across the world in the period 1990-2017 and the proportion of people living on less than 1.90 USD a day at 2011 PPP (Purchasing Power Parity) had decreased from $36.2 \%$ to $9.2 \%$, an average of one percentage point every year ${ }^{1}$. The progress in global poverty reduction is attributed to steady economic growth and many developing countries' gaining wealth, especially countries in East Asia \& Pacific, and South Asia. With the world's largest population, China for example, has experienced rapid economic growth since 1978 when the country launched its reform and opening-up which resulted in a dramatic reduction in the extent of extreme poverty (Ravallion and Chen, 2007). The period 1990-2016 witnessed 745.1 million people moving out of poverty in China and the poverty rate decreased from $66.3 \%$ to $0.5 \%$.

The causes of poverty are multi-dimensional. Individuals' lack of capabilities and skills, lack of effort, and poor money management can lead to impoverished situations. Severe land degradation is found to aggravate rural poverty (Liu and Wang, 2019). Unfavorable and unforeseen circumstances such as illness, bad luck, or lack of opportunities also cause poverty (Halman and Van Oorschot, 1999; Shek, 2004; Davids and Gouws, 2013). From a macro perspective, Myrdal attributed poverty to global inequality where resources among nations are distributed unevenly (Myrdal, 1970), leading to socioeconomic inequalities among certain segments of the world's population. Immanuel Wallerstein (1979) considered the global economy as a complex system in which there exists an economic hierarchy wherein certain countries hold power with sufficient resources while other countries are in economically subordinate positions. Great challenges and obstacles to mobilization and development exist for countries in a position of subordination. For example, civil wars and local conflicts regularly occur around the world, leaving millions of people homeless and in desperate need for humanitarian assistance with food relief, medical treatment, and livelihood support, adding to the complexity of poverty in the world.

Poverty is often concentrated in nations with subordinated or marginalized economies, and comparing various explanations as to why people are poor is becoming of increasing importance to researchers. Investigating the characteristics of the poor is important to better understanding the circumstances surrounding the poor. The criterion for identifying the poor is to assess people's cost of living and 1.90 USD a day at 2011 PPP is the world poverty line. However, data availability issues in many countries and difficulties in aggregating available data are big challenges to poverty measurement. At present, measures from the consumptive perspective are used such as nutrition-based poverty measures, basic needs, composite indicators, and income-based measures (Thorpe, 2004). Recent endeavors have sought to use a multidimensional poverty index (Alkire and Santos, 2014), follow people's mobile phone use (Blumenstock et al., 2015), and apply machine learning to high resolution satellite imagery (Jean et al., 2016).

In terms of poverty reduction, economic growth has been considered as the main driving force which can offer poor people jobs, raise funds for infrastructure construction and public services as well as supply education and medical treatment in poverty-stricken areas (Bruno et al., 1996; Dollar and Kraay, 2002). Besides the top-down measures, which are normally

${ }^{1}$ https://databank.worldbank.org/home.aspx 
leveraged by governments and NGOs, the importance of local people's resolution, collaboration, and actions to eliminate poverty is also highlighted (Li et al., 2016b).

Current research contributes to the understanding of poverty and provides practical ways of alleviating poverty (Guo et al., 2018.). Our concern lies in stable poverty reduction since unexpected disasters, wars and conflicts, illnesses and deaths of main income earners can drive people back into impoverished situations. According to the World Bank, 14 countries in 2020 had poverty rates between $9 \%$ and $18 \%$, and 38 countries had poverty rates over $18 \%$. With 433.39 million people living on less than 1.90 USD a day at 2011 PPP, Sub-Saharan Africa is the world's least developed region. Slower economic growth, conflicts, natural hazards, and weak institutions have also aggravated the vulnerability of poverty reduction in this region. Thinking about the United Nations goal to end poverty by 2030 , it is necessary to identify key factors which are influencing global poverty reduction. This paper firstly investigates the spatio-temporal poverty changes in the world and then analyzes key factors affecting stable poverty reduction. Finally, by introducing the concept of resilient poverty reduction, the implications for policy making and improving the world's capacity for sustainable poverty reduction in the future are put forward.

\section{Spatial-temporal dynamics of global poverty}

\subsection{Methodology and data}

The Gravity Model is used to detect global poverty dynamics in the period 1990-2015. The Gravity Model is widely used to analyze flows of factors and spatial laws (He et al., 2011; Grether and Mathys, 2010; Wang et al., 2013). Although poverty reduction is nation based, it is a global issue as all nations are tightly connected in terms of trade, population mobility, information exchanges and so on. The Gravity Model treats the world's poverty reduction as a whole and helps to identify how it evolves. The movement of the gravity center reflects the spatial trajectory of global poverty dynamics. Regarding the impoverished population and GDP as the "mass" of each region, the poverty gravity center and economic gravity center are the joint force points of the poverty and the economic sub-vectors in the world, and also the balance point of the force. At the gravity center, the forces in all directions can be balanced.

The World Bank offers estimation data of poverty at the regional level by using the 1.9 USD/day poverty line at 2011 PPP. According to the World Bank, the statistics of the impoverished population are distributed in six regions including Middle East \& North Africa, South Asia, Sub-Saharan Africa, Latin America \& Caribbean, Europe \& Central Asia, and East Asia \& Pacific, while North America is not included. The Gravity Model is given below:

$$
\begin{aligned}
& x_{j}=\sum_{n}^{i=1}\left(P_{i j} \cdot x_{i}\right) / \sum_{n}^{i=1} P_{i j} \\
& y_{j}=\sum_{n}^{i=1}\left(P_{i j} \cdot y_{i}\right) / \sum_{n}^{i=1} P_{i j}
\end{aligned}
$$

where $P_{i j}(i=1,2,3, \ldots, n)$ indicates the amount of impoverished population of the region $i$ at 
year $j$ while $x_{i}, y_{i}$ represent the longitude and latitude of the geographic coordinates of the region's administrative capital (considered as a point). $G_{j}=\left(x_{j}, y_{j}\right)$ is the poverty gravity center at year $j$. Then, the moving distance $d_{t}$ can be calculated with the poverty geographic coordinates at year $t$ and $t-1$.

$$
d_{t}=\sqrt{\left(x_{t}-x_{t-1}\right)^{2}+\left(y_{t}-y_{t-1}\right)^{2}}
$$

To predict the movement trend of the world's poverty gravity center, we use the Malthusian population model to predict the poor population with the assumption that the population growth rate is constant. The population is predicted by an exponential growth function. Suppose $r$ is the population growth rate and $P(t)$ is the number of poor people in $t$ years. The specific model is as follows:

$$
[P(t+\Delta t)-P(t)] / P(t)=r \Delta t
$$

The above equation can be formulated into an exponential form:

$$
P(t)=P_{0} e^{r t}
$$

We choose the same method to calculate the world's economic gravity center using equations (1) and (2), where $P_{i}$ is no longer used to represent the amount of impoverished population of region $i$, but rather the GDP of region $i$. The population, poverty population, and GDP data are collected from the World Bank and the geographic coordinate data are extracted from ArcGIS.

The main research procedure of this methodology is as follows:

(a) Use the Gravity Model to calculate the global poverty gravity center, and trace global poverty dynamics

(b) Identify key factors which are influencing global poverty reduction

(c) Propose the "STAR" scheme for resilient global poverty reduction.

\subsection{Results}

Figure 1 shows the movement of the world's poverty gravity center for the period 1990-2015 and its prediction for the period 2015-2050. As clearly shown, the world's poverty gravity center moves continuously from South Asia to the African continent. In 1990, the world's poverty gravity center was in Jharkhand, India and it reached central Maharashtra, India in 2000. Then, the poverty gravity center arrived in Somali Peninsula, Eastern Africa in 2013, and moved further to the east part of Ethiopia in 2015. In 25 years, the world's poverty gravity center moved to the southwest by $5033.32 \mathrm{~km}(1572.37 \mathrm{~km}$ to the south, $4781.42 \mathrm{~km}$ to the west).

During the last decade of the 20th century and the beginning of the 21st century, the world's poverty gravity center was in South Asia. South Asia is a region of large population and used to suffer from colonization, wars, and disasters which resulted in underdevelopment with deep poverty. In 1990, the number of poor people in South Asia living on less than 1.90 USD a day at 2011 PPP was about 536 million, accounting for $30 \%$ of the total poor in the world.

In over two decades' time, Africa (especially Sub-Saharan Africa) has replaced Asia and become the key region of the world for poverty. In 2005, Sub-Saharan Africa surpassed East Asia \& Pacific and then South Asia in 2011 as the region of the world with the poorest people. East Asia \& Pacific and South Asia accounted for $80 \%$ of extreme poverty in the 


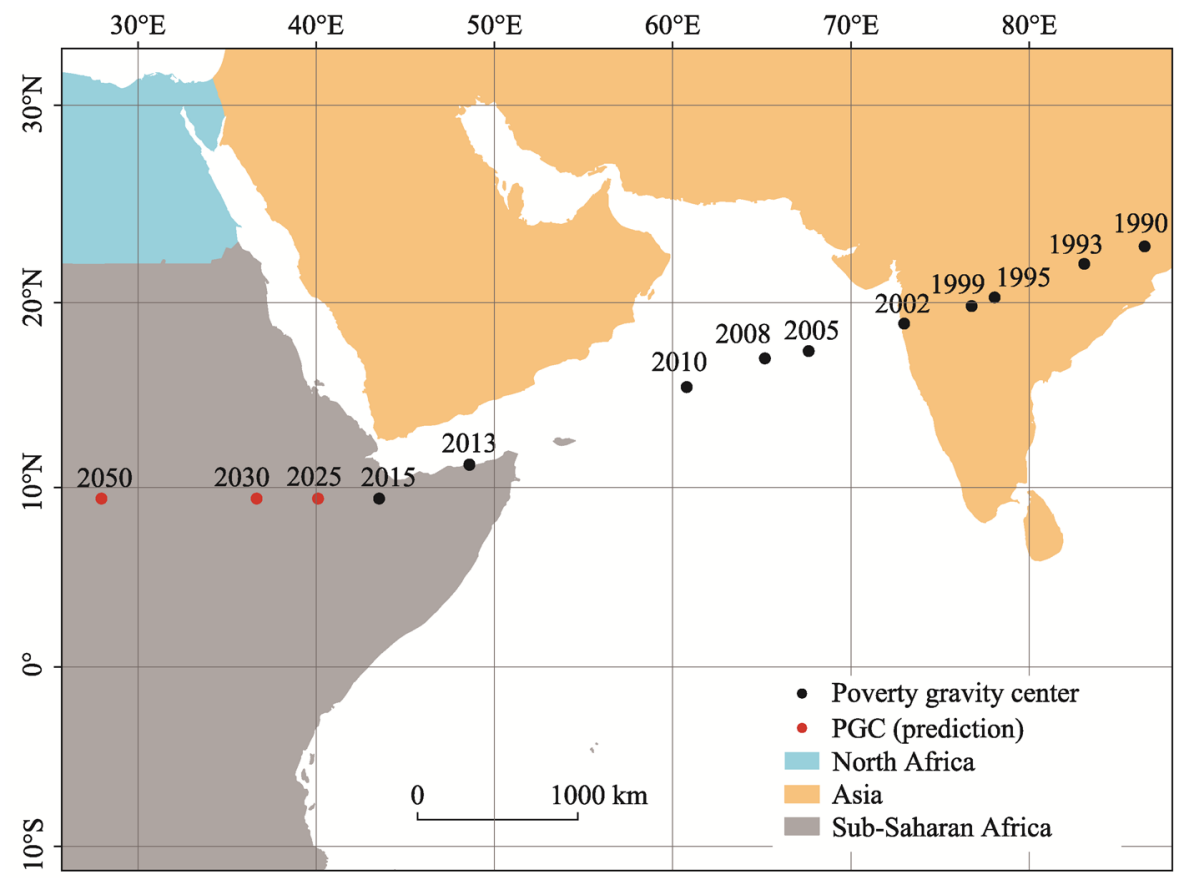

Figure 1 Movement and prediction of the world's poverty gravity center

world in 1990 while Sub-Saharan Africa accounted for $56.11 \%$ of the global poor in 2015 . With the launch of a series of poverty reduction strategies in East and South Asia, the number of people below the world's poverty line was greatly reduced and the focus of the world's poverty center shifted to Africa.

According to Figure 2, significant poverty reduction is seen in East Asia \& Pacific, and South Asia in the period 1990-2015. With 940 million and 320 million people out of poverty, East Asia \& Pacific and South Asia have reduced their poverty rate from $61.5 \%$ to $2.3 \%$, and from $47.3 \%$ to $12.4 \%$ respectively. The regions of Middle East \& North Africa, Latin America \& Caribbean, and Europe \& Central Asia all experienced poverty reduction in the research period, but with a smaller scale compared with East Asia \& Pacific and South Asia. By contrast, Sub-Saharan Africa saw an increase in the poor population from 278 million to 413 million in the period 1990-2015. That is why the world's poverty gravity center moves directly from the northeast of the world to the southwest.

As the red dots in Figure 1 show, the world's poverty gravity center is predicted to move westward and reach the central and western parts of Ethiopia in 2025 and 2030 respectively. It will continue with the trend and move further to the west after 2030 and arrive in the center of Sub-Saharan Africa in 2050. The prediction indicates the aggravated poverty situation in Sub-Saharan Africa in the future and this region remains the essential battlefield for global poverty reduction.

\section{Challenges to sustainable poverty reduction}

\subsection{Monitoring the global poor becomes complex}

Accurate identification of poor people and monitoring their livelihood is a basis for sustain- 


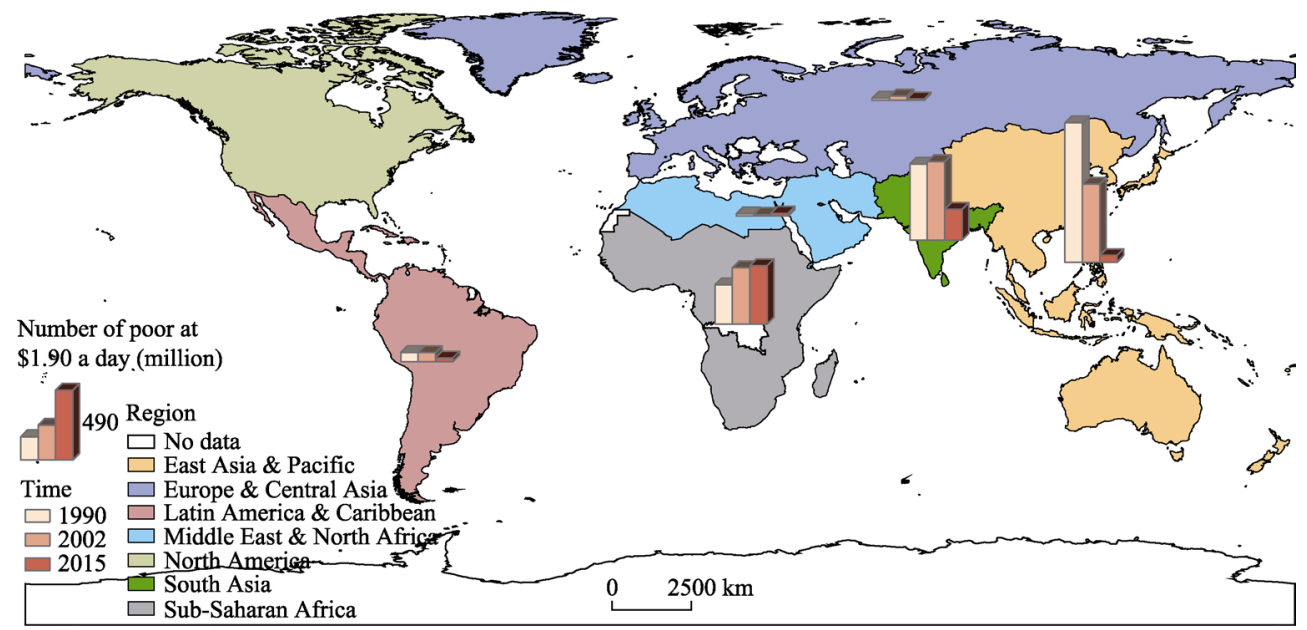

Figure 2 Global poverty dynamics, 1990-2015

Note: North America is not included in the World Bank's poverty statistics.

able poverty reduction. The number of forcibly displaced people has increased substantially from 33.9 million to 65.6 million across the world in the period 1997-2016 (UNHCR, 2016). The civil war in Syria since 2011 and the conflicts in South Sudan, Somalia, Congo (Kinshasa), Nigeria, and the Central African Republic have resulted in the number of displaced people in Africa reaching a record high. There were 12 million forcibly displaced Syrians at the end of 2016, more than in any other country in the world. Colombians were the second largest group (7.7 million), followed by 4.7 million Afghans and 4.2 million Iraqis. In the meantime, the global population suffering from hunger is surging, rising from 777 million in 2015 to 815 million in 2016, with conflicts being the main reason for the increase (FAO and WFP, 2018). As a result, extreme poverty is now increasingly concentrated in these vulnerable groups and humanitarian assistance with food relief and livelihood support to those suffering from persecution, conflicts, violence, and human rights violations remains extremely critical.

The recent surge in displacements makes it hard to monitor the poor who are either internally displaced or cross-country relocated, and it becomes more difficult to reach those who often live in fragile contexts and remote areas. As the developing regions host $84 \%$ of the world's refugees, with about 4.5 million people, the displacements exert a huge burden on the neighboring countries with limited resources to host displaced people.

\subsection{Economic marginalization aggravates poverty}

Poor often means deprivation of development opportunities, which also applies to the least developed nations and regions. It is evident that the world's economic growth has been unevenly distributed. As Figure 3 shows, the world's economic gravity center has remained in the Global North - south part of Europe in the period 1990-2015. Sub-Saharan Africa, the world's poverty gravity center, has been excluded or been marginalized from global economic growth.

Economic growth in Sub-Saharan Africa is relatively dependent on extractive industries such as ore, metals, and fuels (Jesús and Martin, 2019). Such industries benefit few and have 
limited ties to the impoverished population. As for people's livelihoods, World Bank data show that $57.4 \%$ of people in Sub-Saharan Africa still rely on agriculture. The percentage of annual freshwater withdrawals for agricultural use to total freshwater withdrawal in this region was $73.05 \%$ in 2015 and this number reached $91.82 \%$ in 2016 . This agricultural system may easily collapse when there is drought or even water shortages and consequently many people would be driven to an impoverished situation. Under these circumstances, economic marginalization will aggravate the poverty situation in Sub-Saharan Africa and push the world's poverty gravity center further into this region.

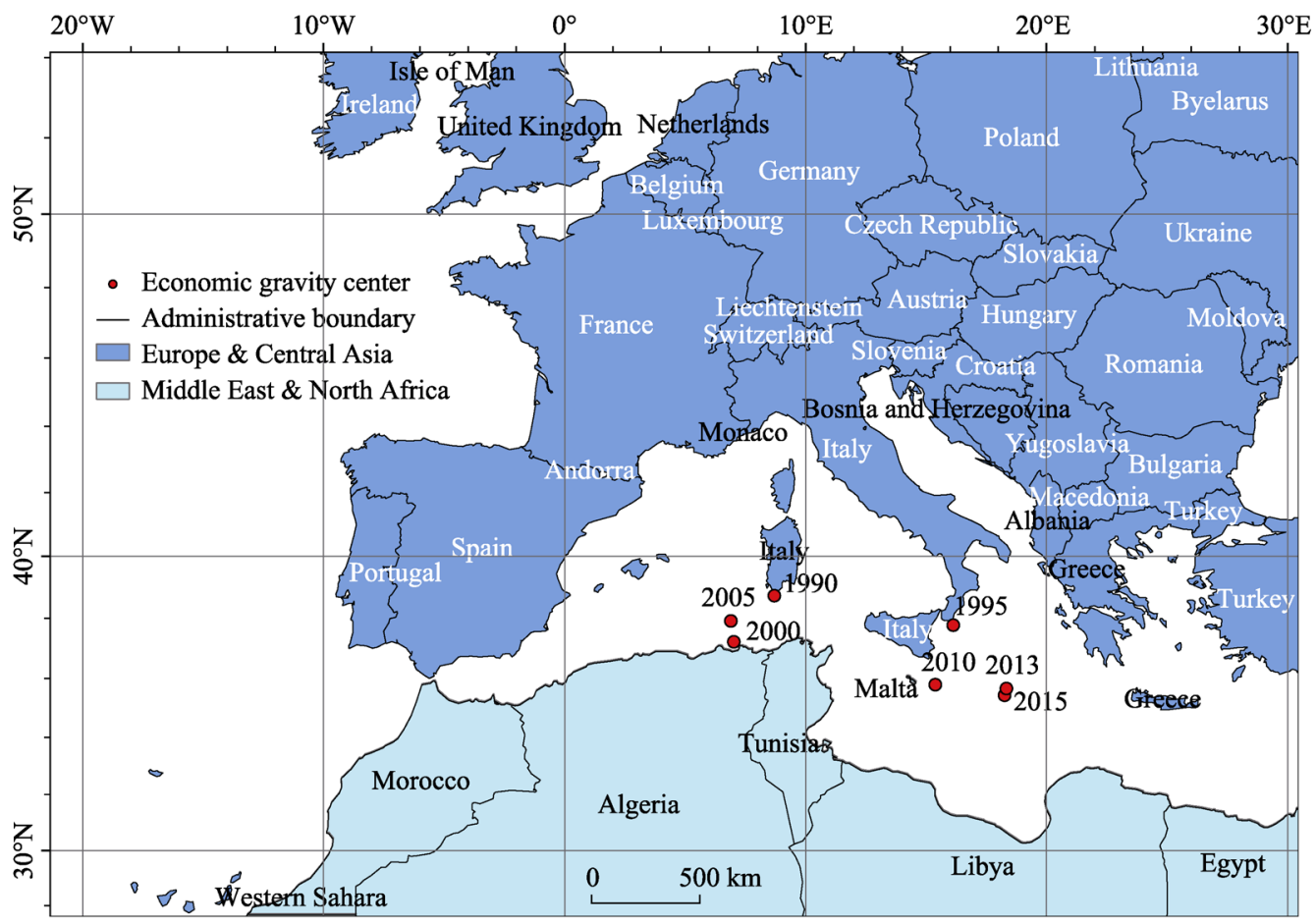

Figure 3 The movement of the world's economic gravity center, 1990-2015

\subsection{Rural decline affects the stability of poverty reduction}

At present, impoverished households are mainly located in rural areas and a large number of children suffer from ill-served essentials such as health care, education, and sanitation. World Bank data indicate that $79 \%$ of the global poor live in rural areas and $67 \%$ are employed in agriculture. Rural poverty rates are over three times higher than in urban areas: $17.2 \%$ versus 5.3\%, respectively (World Bank Group, 2018). People making a living through agriculture are more likely to fall into poverty compared with people in other economic sectors. This implies that it takes more energy to lift people out of poverty when they are residing in villages and undertaking agriculture for maintaining their livelihood.

With the evolution from agrarian to urban-industrial economies, and to the knowledge economy, rural decline becomes an inevitable process which has swept both developed and developing countries (Li et al., 2019). In this process, rural communities are becoming less 
viable because large numbers of the young and talented migrate to cities. The consequences are especially serious in least developed countries where migration is survival-oriented instead of opportunity driven (Liu and Li, 2017). As a result, villages' capacity to deal with external shocks drops, and poverty alleviation in villages is affected by depopulation, industrial recession, and social degradation. What's more, rural poverty reduction is often temporary: economic fluctuations, conflicts, and climate change can easily rob people of their hard-won gains and force them back into poverty.

At present, knowledge-intensive industries which are innovation-oriented are becoming the main content of the global economy (Westlund, 2006). Big city-regions are dominating the knowledge economy because of their potential for face-to-face contacts and new combinations of human knowledge. Thus, interaction and trade among cities are the main forms of exchange at both global and national levels, while rural hinterlands have lost their importance and the share of urban-rural interaction and trade has decreased (Westlund and Kobayashi, 2013). In this sense, it is difficult for those impoverished rural hinterlands in remote areas to get involved in the knowledge economy particularly when they are losing young and fit laborers.

\subsection{Climate change complicates poverty reduction}

The impact of climate change on poverty should not be underestimated. Recent history has seen a surge in the consumption of global fossil energy which has intensified global climate change, and triggered extreme weather events, epidemics, and biodiversity destruction. In this process, poor people may be heavily affected when they are more often exposed to floods, droughts, and extreme heat (Hallegatte and Rozenberg, 2017). People will also be kept in poor situations by climate-related shocks which normally take away people's stock of assets or create irreversible impacts on human capital through health or educational impacts (Sen, 2003; Krishna, 2006). A World Bank report estimated that, if unaddressed, climate change has the potential to push between 68-132 million people into poverty by 2030 (World Bank Group, 2020).

The impact of climate change on agriculture is another concern from the perspective of poverty. Climate change has caused increased frequency of extreme weather and natural disasters which results in crop yield loss. Simulating the impact of climate change on food production shows that global yield changes will become negative from the 2030s onwards. In the second half of the 21 st century, the percentage of crop yield decline will reach $10 \%$ to $30 \%$ (Challinor et al., 2014). As a result, those whose livelihoods depend on agriculture will suffer income reduction and may easily fall into poverty. To make matters worse, poor people tend to have limited access to modern agricultural technology and post-shock support such as loans to meet the challenge and recover from disasters.

\section{Resilience building for sustainable poverty reduction}

Generally, the movement to eliminate extreme poverty is far from over since it becomes hard to root out poverty in places facing violent conflicts and with weak institutions. The World Bank (2018) offers an estimation of all countries' poverty reduction rate growing at an average pace of $8 \%$ to accomplish the world poverty reduction target by 2030 . However, this is not feasible. Global economic fluctuations, uneven distribution of growth, and rural decline 
as well as climate change are jointly influencing the stability of global poverty reduction, making those who remain in extreme poverty more vulnerable to external shocks. It is thus necessary to take deliberate policy action and new approaches to reverse the tide and improve the resilience capacity for sustainable poverty reduction around the world.

The word resilience is derived from the Latin word "resilire," which indicates rebound or jumping back. This concept was first applied to the field of classic physics in 1824. It was defined as the ability of a substance to return to its original equilibrium state after being deformed by pressure shock (Modica and Reggiani, 2014). With the development of disciplines, resilience research has expanded to ecology, economics, environment, society, and disasters, and has become an important concept for understanding social-ecological systems and sustainability (Folke, 2006). Here, resilient poverty reduction at the individual level means people who are out of poverty have the ability to stay in a state of resilience against external shocks so as to avoid returning to poverty. Regarding resilient poverty reduction at national or regional levels, this indicates that a country or a region can offer conditions to those out of poverty to develop and approach better-off livelihoods. This is the prerequisite for individuals to maintain a living status of resilient poverty reduction.

By evaluating current challenges vis-à-vis global poverty reduction, prioritized measures for enhancing the resilience of poverty reduction need to be stipulated to maintain countries' political stability, improve the poverty reduction effect, carry out regular assessments of global poverty reduction, and revitalize the declining countryside. We hereby put forward the "STAR" scheme (Figure 4).

"S" means political stability which is a prerequisite for a nation to develop their economy and alleviate poverty. At present, Sub-Saharan Africa is the "short board" of the world's poverty reduction. And it becomes more challenging to implement poverty alleviation measures in a region where political instability, weak institutions, fragile economy, conflicts, and natural disasters exist. Thus, priorities must be given to joint actions taken by the United Nations and regional powers to maintain political stability and avoid conflicts in Sub-Saharan Africa and other regions of the world.

" $T$ " means a targeted poverty alleviation system. It is noteworthy that there are diverse needs of impoverished groups of which poverty causes are also different. This has added difficulties in identifying poverty and effectively implementing poverty alleviation measures across the world. Thus, we call for the establishment of a targeted poverty alleviation system to identify poor households and communities of which there are people living on less than 1.90 USD a day at 2011 PPP. Then, a partner assistance mechanism needs to be created by linking developed nations, NGOs, and transnational corporations with the least developed nations and impoverished groups. This is to help those least developed countries or places to get involved in the world's economic growth instead of being economically marginalized. Then, specific measures such as financial aid, investment, labor training, infrastructure construction, and medical assistance are taken to meet the diverse needs of poor people. Targeted poverty alleviation is to ensure that accurate assistance reaches impoverished people. Since 2015, China's practice has proved the efficiency and effectiveness of targeted poverty alleviation (Li et al., 2016b).

"A" means assessment of the poverty alleviation effect. The World Bank issues annual reports on poverty alleviation at the global level as a whole and at the regional level in detail. 


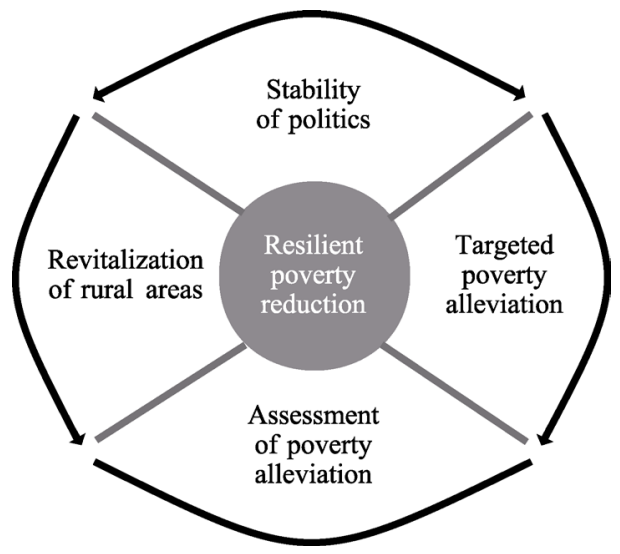

Figure 4 The "STAR" scheme for resilient poverty reduction
It is necessary to extend this assessment to the national level following the same criteria. This should track progress towards poverty alleviation and monitor the constituents of, and changes in, national poverty, people's occupations and income, poverty causes, and real needs as well as the assistance effect. Then, annual assessments of global poverty reduction would help to make in-time adjustments of poverty alleviation measures and national policies.

"R" means revitalization of rural areas. The majority of the world's poor population reside in rural areas and agriculture is their main means of livelihood. Rural decline owing to various reasons will undoubtedly affect their efforts toward better lives and make poverty reduction unstable. Rural revitalization focusing on poverty-stricken areas includes many facets such as creating more, better, and inclusive jobs, investing in human capital, improving human training, infrastructure, and financial situations, and supporting a strong private sector. The purpose of rural revitalization is to lay a solid foundation for poor and marginalized groups to change their fragile situations and build diversified routes leading to improved livelihoods.

The above-mentioned parts jointly support resilient poverty reduction in the world. Stability of politics is the basis for implementing targeted poverty alleviation and rural revitalization which further supports the assessment of poverty alleviation. Feedback concerning the dynamics of global poverty reduction is obtained by undertaking regular assessments of poverty-related policies and measures. This helps to ensure the accuracy and effectiveness of poverty alleviation.

\section{Discussion and conclusions}

The world has made marvelous achievements in the reduction of the total number of the poor living on less than 1.90 USD a day at 2011 PPP in the period 1990-2015. This would not have been possible without long-term collaboration and great efforts from the United Nations and countries committed to poverty reduction. However, poverty reduction has been unevenly distributed around the world. In 25 years, the world's poverty gravity center moved to the southwest by $5033.32 \mathrm{~km}$. Dramatic reductions in poverty occurred in East Asia \& Pacific and South Asia while extreme poverty is still widespread in Africa. As a result, the world's poverty gravity center has shifted from South Asia to Sub-Saharan Africa and according to prediction, will move further into the African continent in the post-2030 era. By contrast, the world's economic gravity center remained in the Global North - south part of Europe in the period 1990-2015.

Looking ahead to 2030 when the goal of eliminating extreme poverty is set to be accomplished, many challenges exist and exert profound and far-reaching impacts on sustainable poverty reduction in the world. To a large extent, we cannot be that optimistic about reaching the world's poverty reduction goal as we approach more closely to it. Political instability 
and conflicts, economic marginalization and fluctuations, as well as climate change shocks have been torturing poverty concentrated countries, and make poverty reduction more vulnerable. What's more, the current COVID-19 pandemic continues to exert unforeseen impacts on every aspect of human life. As for the poor, it becomes more difficult to find suitable jobs to maintain their livelihood as the world's economy has declined. It is thus necessary to evaluate the world's poverty reduction and put forward a clear and feasible route for the next decade.

Based on the analysis, we highlight the necessity of resilience building of poverty reduction as a critical component in the success of achieving the world's poverty reduction goal by 2030 . The "STAR" scheme offers a new and comprehensive perspective which includes maintaining political stability, promoting targeted poverty alleviation, implementing regular assessments of the poverty reduction effect, and revitalizing rural and poverty-stricken areas. This scheme is a targeted response to the changing geography of global poverty in recent decades and it helps to enhance the resilience of global poverty reduction.

Further concern lies in how we can decrease inequalities between the rich and the poor, the developed and least developed countries or regions so as to approach shared prosperity in the world. This is not as simple as distributing resources from the rich to the poor. Instead, there needs to be a mechanism to involve the poor in the world's economic growth. In this sense, it is necessary for the United Nations and regional powers to play leading roles in creating a coordinated mechanism to link the developed nations with the least developed nations in terms of point-to-point trade and assistance. In the meantime, impoverished countries and regions must be self-motivated and configure clear and feasible development plans which involve poverty reduction as an important constituent.

\section{References}

Agola N O, Awange, J L, 2014. Globalized Poverty and Environment 21st Century Challenges and Innovative Solutions. Berlin: Springer.

Alkire S, Santos M E, 2014. Measuring acute poverty in the developing world: Robustness and scope of the multidimensional poverty index. World Development, 59(1): 251-274.

Blumenstock J, Cadamuro G, On R, 2015. Predicting poverty and wealth from mobile phone metadata. Science, 350(6264): 1073-1076.

Bruno M, Ravallion M, Squire L, 1996. Equity and growth in developing countries: Old and new perspectives on the policy issues. Washington: World Bank.

Challinor A J, Watson J, Lobell D B et al., 2014. A meta-analysis of crop yield under climate change and adaptation. Nature Climate Change, 4(4): 287-291.

Davids Y D, Gouws A, 2013. Monitoring perceptions of the causes of poverty in South Africa. Social Indicators Research, 110(3): 1201-1220.

Dollar D, Kraay A, 2002. Growth is good for the poor. Journal of Economic Growth, 7(3): 195-225.

FAO, WFP, 2018. Monitoring food security in countries with conflict situations: A joint FAO/WFP update for the United Nations Security Council. New York: Food and Agriculture Organization of the United Nations, World Food Programme.

Folke C, 2006. Resilience: The emergence of a perspective for social-ecological systems analyses. Global Environmental Change, 16(3): 253-267.

Grether G M, Mathys A, 2010. Is the world's economic center of gravity already in Asia? Area, 42(1): 47-50.

Guo Y Z, Zhou Y, Cao Z, 2018. Geographical patterns and anti-poverty targeting post-2020 in China. Journal of 
Geographical Sciences, 28(12): 1810-1824.

Hallegatte S, Rozenberg J, 2017. Climate change through a poverty lens. Nature Climate Change, 7(4): 250-256.

Halman L, Van Oorschot W, 1999. Popular perceptions of poverty in Dutch society. Work and Organization Research Centre, Tilburg University, Work Paper 16. http://ideas.repec.org/s/dgr/kubwor.html. Accessed 10 July 2005.

He Y B, Chen Y Q, Tang H J et al., 2011. Exploring spatial change and gravity center movement for ecosystem services value using a spatially explicit ecosystem services value index and gravity model. Environmental Monitoring and Assessment, 175(1): 563-571.

Jean N, Burke M, Xie M et al., 2016. Combining satellite imagery and machine learning to predict poverty. Science, 353(6301): 790-794.

Jesús C C, Martin H, 2019. Deforestation and economic development: Evidence from national borders. Land Use Policy, 84: e347-e353.

Krishna A, 2006. Pathways out of and into poverty in 36 villages of Andhra Pradesh, India. World Development, 34(2): 271-288.

Li Y H, Su B Z, Liu Y S, 2016a. Realizing targeted poverty alleviation in China: People's voices, implementation challenges and policy implications. China Agricultural Economic Review, 8(3): 443-454.

Li Y H, Westlund H, Liu Y S, 2019. Why some rural areas decline while some others not: An overview of rural evolution in the world. Journal of Rural Studies, 68: 135-143.

Li Y H, Westlund H, Zheng X Y et al., 2016b. Bottom-up initiatives and revival in the face of rural decline: Case studies from China and Sweden. Journal of Rural Studies, 47: 506-513.

Liu Y S, Li Y H, 2017. Revitalize the world's countryside. Nature, 548(7667): 275-277.

Liu Y S, Wang Y S, 2019. Rural land engineering and poverty alleviation: Lessons from typical regions in China. Journal of Geographical Sciences, 29(5): 643-657.

Modica M, Reggiani A, 2014. Spatial economic resilience: Overview and perspectives. Networks and Spatial Economics, 15(2): 211-233.

Myrdal G, 1970. The challenge of world poverty: A world anti-poverty program in outline. New York: Vintage Books.

Ravallion M, Chen S, 2007. China's (uneven) progress against poverty. Journal of Development Economics, 82(1): $1-42$.

Sen B, 2003. Drivers of escape and descent: Changing household fortunes in rural Bangladesh. World Development, 31(3): 513-534.

Shek D T, 2004. Beliefs about the causes of poverty in parents and adolescents experiencing economic disadvantage in Hong Kong. The Journal of Genetic Psychology, 165(3): 272-292.

Thorpe A, 2004. The Nature and Causes of Poverty: An Overview. Poverty and Small-scale Fisheries in West Africa. Dordrecht: Springer, 9-36.

Tollefson J, 2015. UN approves global to-do list for next 15 years. Nature, 525(7570): 434-435.

UNHCR, 2016. The UN Refugee Agency, Global Trend: Forced Displacement in 2016. Geneva: UNHCR.

Wallerstein I, 1979. The Capitalist World Economy. Cambridge: Cambridge University Press.

Wang Y, Chen Y N, Li Z, 2013. Evolvement characteristics of population and economic gravity centers in Tarim River Basin, Uygur Autonomous Region of Xinjiang, China. Chinese Geographical Science, 23(6): 765-772.

Westlund H, 2006. Social Capital in the Knowledge Economy: Theory and Empirics. Cheltenham: Edward Elgar.

Westlund H, Kobayashi K, 2013. Social Capital and Rural Development in the Knowledge Society. Cheltenham: Edward Elgar.

World Bank Group, 2018. Poverty and shared prosperity 2018 piecing together poverty puzzle. Washington DC: World Bank Group.

World Bank Group, 2020. Poverty and Shared Prosperity 2020. Washington DC: World Bank Group. 